\title{
Thoughts on Improving Performance Assessment of Civil Servants in China
}

\author{
LI Liqin
}

Xi'an International University, Xi'an, 710077, Shaanxi, China

\begin{abstract}
There are a number of defects in the current assessment mechanism of civil servants' performance in China. These defects exist in various aspects of the assessment mechanism, such as objects, contents, criteria, indicators for performance appraisal, methods, results and feedback. In this study, scientific performance assessment mechanism was discussed on the basis of innovative performance assessment model, developed by Nanchang Administration for Industry and Commerce.
\end{abstract}

KEYWORDS: performance assessment; civil servant; innovation

\section{INTRODUCTION}

Performance assessment of civil servant is important not only theoretically but also practically. It influences the evaluation efficiency of government officials, performance of government departments and satisfaction degree of the public for government performance.

\section{CURRENT CONDITION OF CIVIL SERVANT PERFORMANCE ASSESSMENT IN CHINA}

Performance assessment of civil servants in China has appeared since 1990s. There was no unified assessment system at first. Under the instruction of the Interim Provisions on National Public Servant Appraisal, government departments in different areas conducted assessment based on their specific situations [1]. More policies about public servant performance assessment have been issued after that during the assessment process. The Notice of Problems about Performance Assessment System of National Civil Servants was issued by Ministry of Personnel of the People's Public of China in 1994; Supplementary Notice of Problems about Performance Assessment System of National Civil Servants in 1996; Opinions on Further Strengthening the Performance Assessment of National Civil Servants in 2000. There were still other implementation advices given by local governments and departments. These documents had formed a complete system of civil servant performance assessment by regulating principles, contents, criteria, methods, procedures and the application of outcomes. Performance assessment of civil servants has been listed in Civil Servant Law of the PRC in 2006. It defined that performance of civil servants should be assessed comprehensively in morality, ability, diligence, performance and integrity. Among those indicators, working performance assessment was mostly emphasized. The initially established performance assessment system of civil servant in China has been improved in practice. However, there are a series of problems in objects, contends, criteria, indicators, methods, results and feedbacks in the performance assessment system. Thus many assessments were mere formality without expected outcomes. Instead of motivating civil servants to improve working efficiency, it has become a burden of work management. Civil servant performance assessment system is discussed to solve those problems based on the innovative practice of Nanchang Administration for Industry and Commerce in this study.

\section{INNOVATIVE ASSESSMENT SYSTEM OF CIVIL SERVANT PERFORMANCE OF NANCHANG ADMINISTRATION FOR INDUSTRY AND COMMERCE}

The industry and commerce administrative system in China has cancelled the individual business administrative fee and marketplace administrative fee since September 1, 2008 [2]. Nanchang Administration for Industry and Commerce had to adjust to the new situation. Based on deep thoughts, 
the administration decided to transform from a feecharging administration to a service-providing administration, emphasizing primarily on providing supervision and service to the market. There were improvements of performance assessment mechanism to deal with problems emerging in practice. According to this, Nanchang Administration for Industry and Commerce issued the Primary Level Sub-office Assessment Criteria of Nanchang Administration for Industry and Commerce 2010. These assessment criteria have been implemented in the municipal bureau since 2011 to establish a performance assessment system throughout the industry and commerce administrative system in Nanchang. At the same time, the administrative made a performance assessment plan of leading group and leading cadres in county bureaus and departments. The performance assessment system was further improved in 2012 and 2013. The performance assessment system of civil servants in Nanchang has obtained remarkable achievements and attracted high attention from scholars, experts and governments of other cities and provinces. The following section is an introduction of the main contents and innovations of the assessment model of civil servant performance.

\subsection{Combining assessment objects of individual civil servant with departments objects}

There are 16 county and district bureaus and 92 primary level sub-offices under Nanchang Administration for Industry and Commerce. To enhance the working efficiency of the whole administration system, Nanchang Administration for Industry and Commerce changed the assessment model [3]. It distributed the department assessment indicators to individual workers evenly based on position responsibilities and abilities of civil servants in the administration departments. Moreover, the assessment system connected the assessment results of departments and individuals [1]. According to this practice, assessment results of individual workers were determined by not only their own work but also the performance of the department they work in. For example, in a primary level sub-office there was a hark-working civil servant. Since the department assessment result lagged behind in an annual assessment, the assessment result of the civil servant was negatively influenced. Even his/her qualification to be evaluated as an excellent civil servant was cancelled consequently. Therefore, civil servants should pay attention to both their own work and the overall performance of their departments. Hence, civil servants were encouraged to positively contribute to innovation of working methods and efficiency to enhance the overall development of their departments. An "all for one, one for all" culture was developed in the departments consequently.

\subsection{Designing targeted indicators of performance assessment}

It was hard to develop a unified set of assessment indicators due to the various positions, responsibilities and levels. Therefore Nanchang Administration for Industry and Commerce has developed specific assessment indicators targeted to different departments and positions. In line with Civil Servant Law of the PRC, Nanchang Administration for Industry and Commerce conducted assessment from five perspectives, namely morality, ability, diligence, performance and integrity. The 126 indicators in 21 items of the assessment contents could be divided into 3 categories-general indicators, business indicators and administration indicators. Indicators were measured by scores, in which $80 \%$ scores were about business indicators, $10 \%$ about general indicators and another $10 \%$ about administration indicators. 92 primary level sub-offices share 83 indicators, while bureaus and departments have specific assessment indicator sets for their own. Although the practice of "specific assessment indicator for each individual" was relatively hard to be implemented, it was more effective to provide specific results for individuals [2].

\subsection{Enhancing operability by quantifying indicators of performance assessment}

Nanchang Administration for Industry and Commerce combined quantified assessment indicators with work responsibilities to reduce impacts of human factors and enhance the fairness of assessment results. Key elements of assessment system were clarified such as contents, weights, scores, setting basis, data resources, grading standards and people in charge. Every indicator could be evaluated in scores and verified with related materials. In bureau offices, staffs needed to complete their own work and cooperate with colleagues as many tasks in bureau offices were correlated with each other. In light of this, responsibility weights were added to indicators in assessment system for bureau office staffs. Responsibility weight factors for indicators of staffs were generated automatically based on scores of indicators and responsibilities taken by those staffs. Scores of certain individual staff were positively related to responsibility weight factors. Meanwhile, the former equalitarian assessment model was changed by the adoption of workload factors. The quantities and difficulty degree of work (very large, large, normal, small and very small) were quantified as $1.0,0.9,0.8,0.7,0.6$, respectively. The assessment systems were thus very effective by improving the operability of cross-sectional comparison and appraisal ${ }^{[3]}$. 


\subsection{Combining general assessment with annual assessment}

Performance assessment for civil servants was generally held at the end of each year. The long period of assessment could hardly stimulate working enthusiasm for long. In order to cope with this problem, Nanchang Administration for Industry and Commerce conducted assessment monthly, halfyearly and yearly. This normalized administration models were based mainly on monthly assessment. Monthly assessment was held in the first five workdays every month by bureau offices. Bureau leaders evaluated office performance in the previous month online with grads as excellent, good, moderate and poor. No more than $30 \%$ of offices under the charge of certain bureau could be evaluated as excellent. After the monthly assessment, offices made comments on the performance of the offices and individuals in the previous month to make improvement. Half-yearly assessment, including quantified assessment and online appraisal, was organized by municipal bureau in July this year and January of the next year. Quantified assessment was based on grading standards while online appraisal for each bureau was conducted by representatives of bureaus, offices, deputy to the NPC and costumers. Monthly and half-yearly assessment results of bureaus were connected to the assessment results of individual civil servants. Annual performance assessment results of bureaus and individuals were weighting calculated on the basis of monthly and halfyearly assessment results of bureaus and individuals.

\subsection{Informationization assessment methods}

Construction of information platform was necessary for a scientific performance assessment system. "Performance Assessment Management System of Nanchang Administration for Industry and Commerce" was developed in cooperation with the Public Performance and Information Research Center of Fudan University. This high-efficient and convenient system effectively facilitated the civil servant performance assessment in primary level suboffices. There were three platforms in the administration center of digital performance assessment, namely execution platform, command and monitor platform, and satisfaction degree platform. Administrators could easily manage the assessment process from planning, monitoring and assessing to feedbacks collecting. Execution platform was responsible to conduct monthly and quarter assessments. Satisfaction degree platform consisted of work showing section, social supervision and appraisal section and complaint processing section. Command and monitor platform is established to process data, procedures and relevant materials of assessment. The responsibility of data center is administrating assessment results and generating annual results and ranks of primary level civil servants. There were three sources of data. Firstly, a part of data were automatically collected from exist regulating systems, on which basis assessment results were calculated. Secondly, some data were obtained through field collection of assessing staffs. Those data were unchangeable once entered into the system. Thirdly, functional departments also collected data during daily work ${ }^{[4]}$.

\subsection{Combining assessment results with rewards and penalties of civil servants}

In most cases, assessing staffs did not talk to civil servants about their assessment results. Thus the lack of feedback significantly diminished the stimulating function of assessment. Regulation on Rewards and Penalties based on Performance Assessment of Nanchang Administration for Industry and Commerce was issued and implemented to deal with this problem. Assessment results effectively stimulated working enthusiasm of staffs by fully utilizing the results and strictly implementing rewards and penalties. Thus the performance of civil servants could be evaluated and assessed fair and square.

The practice is combining assessment results with appraisals of bureaus and civil servants, material rewards, and penalties. For instance, the person in charge of an advanced bureau in certain year was assessed as excellent. The bureau at the top of the table could have $30 \%$ of its staffs to be excellent civil servants instead of $15 \%$. It is also a great advantage for the leader of the bureau for future promotion. The top two individual civil servants of the bureau were listed reserve cadres. Bureaus made suggestions of staff performance assessment grades on the basis of the individual result ranking. The improvement of performance assessment mechanism effectively stimulated the working enthusiasm of civil servants.

\section{CONCLUSIONS}

All in all, the performance assessment model developed by Nanchang Administration for Industry and Commerce is a good example to be followed in many aspects. Performance assessment of civil servants should combine individual assessments with department assessments. Targeted assessment indicators should be designed and quantified. Annual assessments should be combined with general assessments while assessment results combined with rewards and penalties of civil servants. This study is intended to establish a fair, scientific and high efficient assessment model of civil servant performance. 


\section{REFERENCES}

[1] Liu Donggeng. Quantifying Responsibilities, Recording Work-Exploring New Assessment Model of Civil Servant Performance. Biweekly of Administration for Industry and Commerce, 2011, (23): 11-13

[2] Hong Jixuan, Wang Jujian, Xiong Qiong. Improving Performance Assessment, Serving Economic Development-Report of Performance Assessment Work of
Nanchang Administration for Industry and Commerce. Nanchang Daily, December 23, 2011

[3] Huang Huan. Example of Informationization Improving Scientific Assessment-Analysis on Assessment Model of Primary Level Civil Servant Performance of Nanchang Administration for Industry and Commerce. China Organization and Personnel, November 24, 2011 